\title{
The potential scope of $m$-health initiative into Grameen renewable energy in Bangladesh
}

\author{
Dr. Mahfuz Ashraf \\ Program Coordinator \& Senior lecturer, Entrepreneruship and Innovation \\ Crown Institute of Higher Education Australia \\ Email: mahfuz.ashraf@cihe.edu.au \\ Marufa Hasin \\ Research Assistant, SEHP Australia \\ Email: marufa_hasin@yahoo.com \\ A B Emran Salahuddin \\ KENT Institute, Australia \\ Email:emrans@gmail.com \\ Sohel Ahmed \\ Grameen Shakti, Bangladesh \\ Email: sohel.ahmed@gshakti.org \\ Dr. Soong-Chul Ro \\ Associate Teaching Professor \\ University of Michigan and Shanghai Jiao Tong University Joint Institute, China \\ Email: soong-chul.ro@sjtu.edu.cn

\section{Dr. Pradeep Ray} \\ Professor \\ University of Michigan (UM) and Shanghai Jiao Tong University (SJTU), China \\ Email: pradeep.ray@sjtu.edu.cn \\ Md. Uzir Hossain Uzir \\ Ph. D. Student, Putra Business School, UPM, Malaysia \\ Email:hossainuzir@gmail.com
}

\begin{abstract}
Sustainability or sustainable development is possible only if health issues of mother and their child and the employment or involvement of women can be ensured in society by promoting social business using the easiest technological system like mobile technology. In this paper, we demonstrate how Grameen Shakti (GS) a not-forprofit organization aiming at sustainable development by ensuring environment and technological friendly social business model. Household energy usage, air pollution, and carbon emission can be controlled by Grameen Shakti (GS) which energy saving, convenient, user friendly and cheap. The paper presents an illustration of how carbon emission, air pollution, and ensuring safe and healthy environment for mother and children are all possible through integrating mobile health (m-Health) management which is a part of sustainable development.
\end{abstract}

Keywords: Sustainability, Sustainable development Strategy, Mobile Network(Technology), m-Health, Information System, Public Health, Grameen Shakti, Renewal Energy.

\section{Introduction}

Sustainability is the most significant and influential aspect in any development initiative. The precondition of sustainability is the essence that resides with in the combination of people, environment and technology. For instance, information is a key that connects the dots between people, environment, research, development, and business endeavor, technology plays a vital role by enabling us to gather data and facts on real time basis and see the results of any changes introduced by an initiative, and health hazards, especially for women and children, 
needed to be monitored in real time, provide feedback from specialists/experts, and intervene if necessary when situation gets critical. Since mobile network has already covered 95 percentage of the world's population today ${ }^{1}$, mobile based technology is the logical choice for implementing any sustainable development strategies.

Therefore, this working paper is focusing on formulating the policy of improvement and deployment for maintain the health-related issues using mobile based technology, particularly for mother and child health through an innovative and entrepreneurial business service delivery model namely 'social business'. The main objective of social business is to ensure community development and sustainable economy operated by companies with the motto of 'No Loss, No dividends'.

According to World Business Council for Sustainable Development (WBCSD), a business has a critical role to play as a source of finance, a driver of innovation and technology, and engine of economic growth and employment. ${ }^{3}$ Considering the above strategies, Grameen Shakti (GS), a not-for-profit company developed a sustainable integrated entrepreneur-based business model to promote affordable, clean, and sustainable renewable energy technology to rural people of Bangladesh. GS aims to work for empowering women, creating green jobs, alleviating poverty, reducing green-house emission, ensuring the healthy community by encouraging \& disseminating the sustainable renewable energy solutions in Bangladesh. ${ }^{4}$ This social project is to highlight the interlinkage of social business model and Sustainable development goals \# 3 and 13 in Bangladesh; may contribute to achieve sustainable renewable energy as well as to contribute improvement of overall wellbeing of mother and child.

\section{Air pollution and its effect on public health}

Household energy usage is one of the major contributors of high greenhouse gas emission. In rural areas, the usage of traditional stoves produces high level of indoor pollution. Inefficient burning of BMF on an open fire or traditional stove generates substantial amounts of particulate matter (PM) as well as carbon monoxide, hydrocarbons, oxygenated organics, free radicals and chlorinated organics. The PM component of this smoke is classified according to its size, with inhalable material $<10 \mu \mathrm{m}$ in aerodynamic diameter referred as coarse particulate matter or PM10 while the inhalable material $<2.5 \mu \mathrm{m}$ in aerodynamic diameter referred as fine particulate matter or PM2.5. According to World Health Organization (WHO) guidelines, the maximum acceptable values of PM10 are $50 \mu \mathrm{g} / \mathrm{m} 3$ for 24 -hour average and $20 \mu \mathrm{g} / \mathrm{m} 3$ for annual mean. For PM2.5, the maximum acceptable values are $25 \mu \mathrm{g} / \mathrm{m} 3$ for 24 -hour average and $10 \mu \mathrm{g} / \mathrm{m} 3$ for annual mean. However, it is reported that in many developing countries the peak indoor concentration of PM10 often exceeds $2000 \mu \mathrm{g} / \mathrm{m} 3 .^{5}$

Air pollution is a significant cause of morbidity and mortality and approximately $76 \%$ of all global particulate matter (PM) air pollution occurs indoors in the developing world. ${ }^{6}$ In Bangladesh, like other developing countries, many household use solid fuel including biomass, wood, animal dung and crop residues for cooking and heating due to cost effectiveness and availability. ${ }^{7}$

Literature reported that high levels of indoor air pollution (Carbon monoxide emission) inefficient usages of BMF produce may increase risk of respiratory infections, including pneumonia, tuberculosis and chronic obstructive pulmonary disease, low birth weight, cataracts, cardiovascular events, cancer and all-cause mortality both in adults and children. ${ }^{7}$ Additionally, those disease can affect adversely if pregnant mother and baby exposed to smoke during pregnancy while cooking. It is a common scenario in society that women are the most exposure group of the family as spending long time with cooking. ${ }^{7}$

The World Health Organization (WHO) estimates that indoor air pollution contributes to nearly 4.2 million premature deaths due to exposure to small particulate matter of 2.5 microns or less in diameter PM2.5 and approximately 3.8 million of them were attributable to household air pollution in $2016 .{ }^{8}$ It is also reported that it may possible to reduce the burden of disease from stroke, heart disease, lung cancer, and both chronic and acute respiratory diseases, including asthma by improving air quality. ${ }^{8}$ Therefore, many non-profits organizations have attempted to make cleaner cook stoves by using cleaner fuels and adding chimneys to remove fumes. Compared with traditional stoves, improved cooking stoves (ICS) burns less fuel and reduces time duration for cooking. It is also produced less smoke and improved air quality. Therefore, a potential 
improvement of the health (women, children and cooks) and climate can be achieved. ${ }^{9}$

It is also reported that exposure to the smoke of BMF has badly effects on different birth outcomes associated with low birth weight, intrauterine growth retardation and perinatal mortality. ${ }^{5}$ A study from Guatemala identified an association between birth weight and fuel used. The research data suggested that the use of an open fire produced average levels of PM10 of $1000 \mu \mathrm{g} / \mathrm{m} 3$. The babies of mothers who were using open wood fires have average $63 \mu \mathrm{g}$ less weight compared with babies born to mothers who were using cleaner fuels. ${ }^{10}$

\section{Grameen Shakti (GS) Improved Cook stoves (ICS): a comparative study}

Although the research started since 1960s in developing countries such as India, Nigeria and Papua New Guinea to understand the association of the exposure of indoor smoke and its impact on respiratory diseases, but different interventions are still running to get an effective and accepted way to reduce indoor smoke.

In Bangladesh, the government have released a new Renewable Energy Policy (REP) for better environment for renewable energy technologies and promoting market development for improved cook stoves. ${ }^{7}$ GS is working with other partner organizations and different government agencies to promote Improved Cookstoves (ICS) and renewable energy technology which will mitigate the indoor pollution as well as reduction of morbidity and mortality in rural Bangladesh. GS currently is manufacturing some of the parts such as stovepipes and grills and the firebox of its stove is made from local materials such as clay or mud. GS noticed a potential market of at least 2 million ICSs in the first three years program in Bangladesh. GS targeted local technicians and local manufacturers for expanding ICS. GS has already trained more than 600 local youth especially women to make, sale and repair ICS. These trained technicians will train others as well as produce and marketing ICS on behalf of GS. Many of them will soon start their own business in arrangement with GS and will lay the basis of developing ICS entrepreneurs at the rural level. These local technicians will establish trustable network within their communities, which will help to promote and distribute the ICS effectively. ${ }^{\mathbf{1 1}}$

There are two models of ICSs will distribute, for example one and two pot stoves. These models are combined in the following fashion: a) one-pot stove (one grate and one chimney)

b) two-pot stove (one grate and one chimney)

c) $2 \mathrm{x}$ one-pot stove (two grates and one chimney)

d) One-pot stove + two-pot stove; also known as three pot stoves. ${ }^{7}$

In India a 10 years long program (2010-2020) has been started to supply 150 million improved cooking stoves to reduce the major public health. Research data estimated about $87 \%$ of Indian household will get clean combustion by receiving ICS at the end of the intervention. The intervention also estimated that $30.2 \%$ of acute lower respiratory infections (ALRI), 28.2\% of chronic obstructive pulmonary disease (COPD) and $17.4 \%$ of disability-adjusted life years (DALYs) can be adverted from 2010 to $2020 .^{\mathbf{1 2}}$

In Nepal, data suggested that about $2.7 \%$ of the national burden of disease identified in 2002 including death of 7500 person and loss of 204400 DALYs due to indoor smoke. ${ }^{13}$ Almost every household in Nepal used to have traditional inefficient stoves and $85 \%$ population depends on BMF. ${ }^{\mathbf{1 4}}$ A survey has been conducted in Nepal in 2006-2008 and have explained cooking technology, kitchen design, fuel-type, exposure to PM concentrate and health are associated with indoor pollution. An intervention suggested three kinds of improved stoves are used in Nepal; 1) Biogas Stoves, 2) improved cook stoves, and 3) Improved cook stoves with smoke hoods. ${ }^{9}$

\section{ICS in relation to future m-Health possibilities}

In Bangladesh, the government is committed to reducing the maternal mortality ratio (MMR) but recent data showed that about 196 maternal deaths occurred per 100,000 live births which indicated unchanged condition from 2010-2016 and about 55\% deaths were occurred due to Hemorrhage and eclampsia. On the other hand, a positive sign observed that two-thirds of infant and child mortality rate has been reduced by 2015 . But, indoor air pollution remains a major concern for 25 million households, despite a number of initiatives aimed at addressing it. ${ }^{15}$

At this initial stage of this project, it is suggested to integrate $\mathrm{m}$-health to get successful result in future. The use of mobile technology in healthcare has been increased tremendously and considers a popular way to disseminate massages to mass. Now-a-days, people are more used to get information through massages or using apps compared to read newspaper or leaflets. Wearable 
device with pregnancy app occupying a major market share, is expected to reach US\$30 Billion in the next five years. ${ }^{16}$ For instance, Grameen-Intel project of wearable device known as COEL (Carbon Monoxide Exposure Limiter) have become popular among pregnant mother as a tool of M-health, provides mama massages for safe pregnancy and delivery, which can detect carbon monoxide at household. COEL is a smart bangle, detects carbon monoxide at a harmful level, a red LED light flashes with beeps to alert and asks her to move to a safer area. A warning voice suggest her to open the windows and doors or get outside. A special type of sensor has been used inside the bangle, which is working through the entire pregnancy period without charging. COEL is a water-resistant bangle, 0.8 inches wide and weighs only 38 grams, and made of high quality durable plastic only designed for Bangladeshi women. ${ }^{\mathbf{1 7}}$

Regular ante natal checkup (ANC) is important to understand safe pregnancy and healthy baby. A survey reported that $37 \%$ of women received the recommended number of (4 or more) ANC during pregnancy; half of them are urban compared to one-third from rural areas. For instance, in remote or rural Bangladesh it is a real challenge for pregnant women to access healthcare facilities and midwives. Moreover, those pregnant women have lack of knowledge to understand the importance of seeking medical advice from trained professionals. Therefore, it is often very difficult to access medical support for having a safe pregnancy and delivering a healthy baby. Research data also explored about $22 \%$ pregnant women were receiving ANC at home in 2016, around 50\% of them in rural Rangpur district. However, the likelihood of receiving ANC from a medical skilled person is positively linked with education and income of the family. ${ }^{\mathbf{1 5}}$

Besides, hemorrhage and eclampsia other complications such as high blood pressure, gestational diabetes, swelling, vomiting, lack of growth of the baby, lack of nutrition, high lipid profile during pregnancy may rise difficulties. It is reported that COEL can be set up at the beginning of the pregnancy dates. Except detecting carbon monoxide, COEL also suggested two MAMA messages in every week on proper diet, vaccination, when to see a doctor, and preparations for delivery into Bangla.

Under the umbrella of social business, it is assumed that the application of wearable device for example COEL (smart bangle) may place significance improvement to the entire maternal health issues and reduce MMR in Bangladesh.

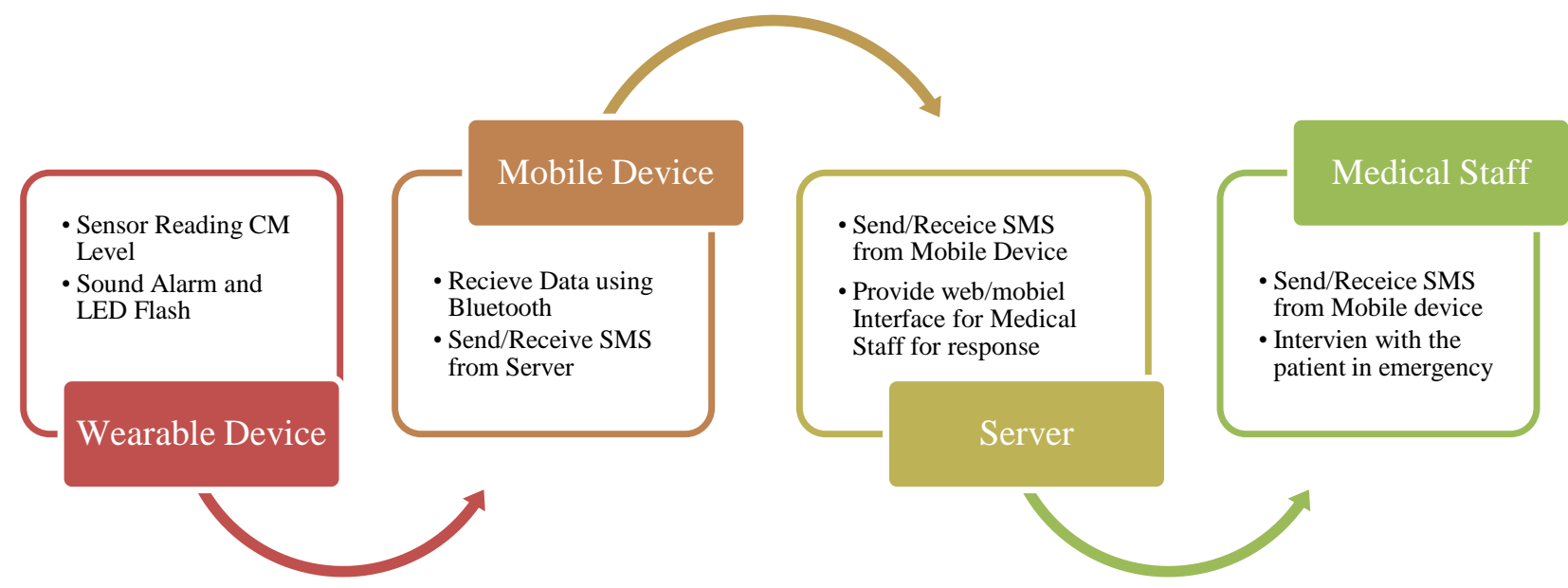

Fig. 1: Information flow diagram of wearable device 


\begin{tabular}{|c|c|}
\hline \multicolumn{2}{|c|}{ Functionality } \\
\hline & $\begin{array}{l}\text { The sensor embedded in the wearable device would monitor the Carbon Monoxide levels and transmit the data } \\
\text { to a mobile device through Bluetooth. At the same time the wearable device will sound Alarm and Flash Red } \\
\text { LED light if the Carbon Monoxide levels reaches at frightening level. }\end{array}$ \\
\hline & The mobile device would upload the data to the server hourly/daily for further analysis by the health experts. \\
\hline & $\begin{array}{l}\text { A dedicated medical or health expert would be associated with a group of users/patients and receive daily } \\
\text { alarm messages from the server. This would allow the expert to intervene the user/patient with instruction to } \\
\text { avoid fatal situations. }\end{array}$ \\
\hline \multicolumn{2}{|c|}{ Users perspective } \\
\hline & $\begin{array}{l}\text { This will allow the patient/user to view historical data relating to Carbon Monoxide levels and alert messages } \\
\text { sent and received by the patient along with description of Carbon Monoxide safety levels. }\end{array}$ \\
\hline & $\begin{array}{l}\text { Provides a messaging platform for the patient/user to interact with the Medical/Health Expert by sending and } \\
\text { receiving messages with the ability of voice control to read out messages (this would help the patients with } \\
\text { limited literacy or Non- literacy). }\end{array}$ \\
\hline \multicolumn{2}{|c|}{ Expert perspective } \\
\hline & $\begin{array}{l}\text { physician with the ability to view alerts received on their client account and respond } \\
\text { from the patient. }\end{array}$ \\
\hline & $\begin{array}{l}\text { Through the client login the physician will be able to set alert conditions that would send alerts automatically } \\
\text { to the patients for some standard alert procedures. Example - Have a rule setting to send high Carbon } \\
\text { Monoxide alert. }\end{array}$ \\
\hline \multicolumn{2}{|c|}{ Security Concerns } \\
\hline & $\begin{array}{l}\text { Since the data is being sent over Mobile networks, it is only as secure as cellular telephone signals. These } \\
\text { messages are vulnerable to hacking. Therefore, the data itself should be encrypted before being sent. Hence } \\
\text { the Grameen Health system would provide an encryption system to send and receive the encrypted SMS from } \\
\text { patient/users for alert messages. }\end{array}$ \\
\hline & $\begin{array}{l}\text { For the Health expert/physicians, the rules can be made a bit more stringent for accessing secure data from the } \\
\text { server. This group of people need to provide ID and Password to access the secured data using a web client } \\
\text { while using desktop or laptop computing with the office facilities. Mobile devices can also be used with } \\
\text { encryption with login procedure using 4-digit pins or biometric security. }\end{array}$ \\
\hline & vho has access and who has ac \\
\hline
\end{tabular}

\section{Concluding remarks: Integrating into the ecosystem}

Women living in the rural and far-flung areas have very little or no support for emergency health support. Their knowledge on critical health conditions during pregnancy, child birth, and child infancy are limited to old traditional or religious believes. ICS along with monitoring and alerting device, COEL, gives us a window of opportunity to save or assist thousands if not millions of these ill-fated, ill-informed, and unknowledgeable, in the context of critical health hazards, from life threatening situation. The toxic fumes from cooking fire triggers more deaths than tuberculosis, malaria, and HIV combined and hence the benefits of the ultra-low-cost COEL wearable will be felt by people across the world. ${ }^{18}$
The Apple CEO Tim Cook said, "Users Will Trust Health Apps More Than Their Doctors in near future," during an Apple event in San Francisco. ${ }^{\mathbf{1 6}}$ The model, which have been discussed earlier, have profound benefits once the COEL wearable device is connected with the mobile network and the real time data feed is enabled. This model would bring miracle by bringing the underprivileged population and the resource persons on the same platform. m-health integration with COEL is well suited for social business as well. For example, Sangpeth, O. and Sangpeth, A. (2016), internet cloud based platform can used successfully to provide remote and customised health care services for Grameen ICS users (Fig 2). ${ }^{19}$ 


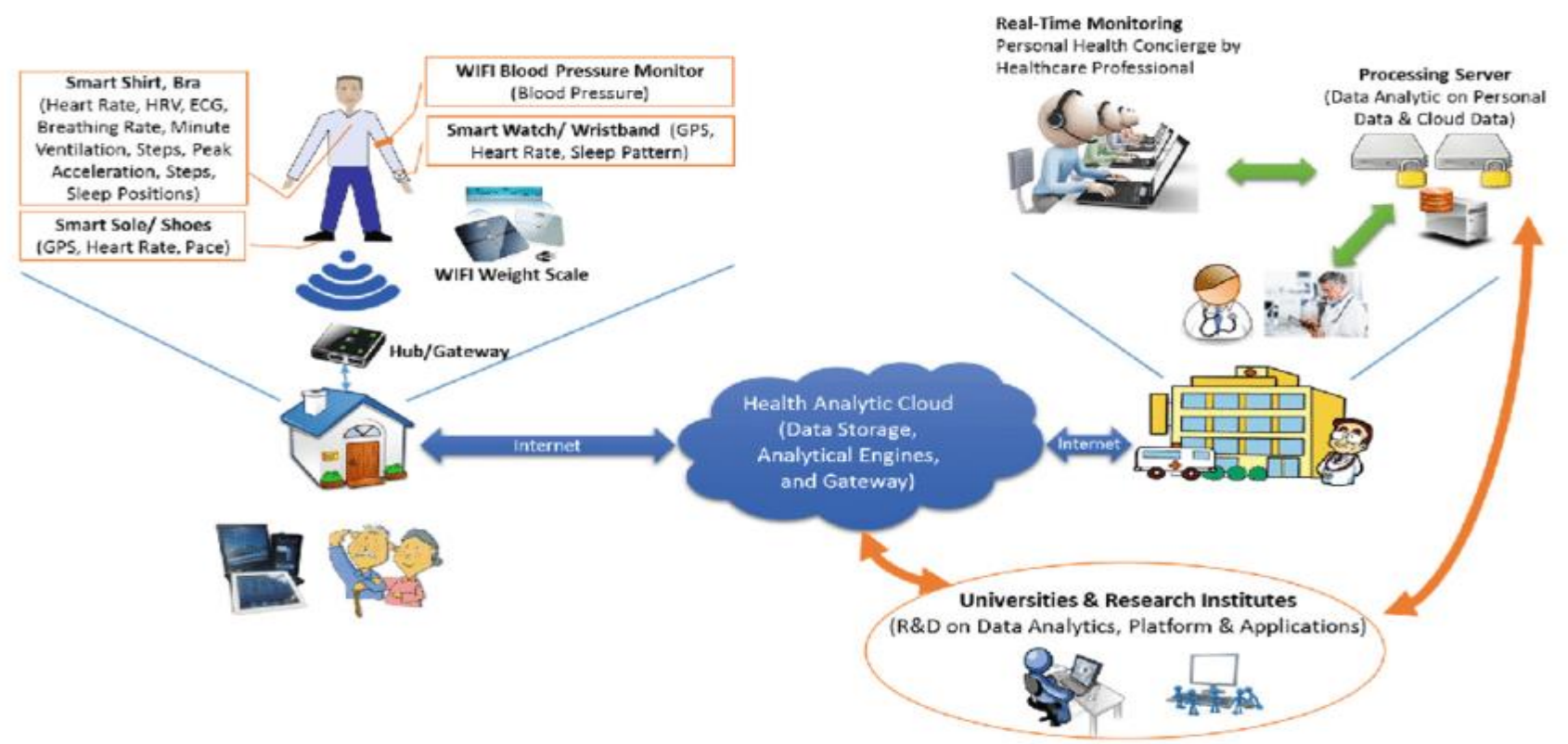

Fig. 2: Utilization of internet and cloud based framework to provide remote and personalized healthcare service.

and extended for different other health issues monitoring, evaluating, and response system such as:

\section{a) Continuous glucose monitoring system (CgSM):} The CGM is made with disposable sensors which is inserted under the skin, typically on the abdomen, to measure glucose levels in the tissue flued in every few minutes. The small sensors are connected to a transmitter that sends the data wirelessly to a handheld

\section{b) Blood pressure, oxygen and Heart Rate Monitoring System:}

The wearable device would use optical sensor and clinically validated algorithm in mobile app would measure blood pressure and heart rate, records the information on mobile based app and uploads into a server that will give dedicated medical staff the access over patient's data and procedures to intervene if necessary. global market for continuous - glucose monitoring global market for continuous glucose monitoring equipment is expected to top $\$ 20.6$ billion by 2022 , according to the report Continuous Glucose Monitoring (CGM): Technologies and Global Markets, and enjoy a compound annual growth rate (CAGR) of $10.1 \% .^{20}$ United States, Europe and Japan are leading at the moment, but Russia, China and India is also coming into play in the global market for CGM usage.

As future expansion of ICS, Grameen Health can be integrated with the model (Fig 1) where the several categories of health services can be formulated. Premium health services can be offered to financially well-off population and the profit can be reinvested to subsidize the Basic health service to the population living under the poverty lines in urban or rural areas. By implementing the model, the true nature of social business can be realized and ultimate goal of sustainable development can be achieved. 


\section{References}

1. Ericsson Mobility Report June 2017. Retrieved from https://www.ericsson.com/en/mobilityreport/population-coverage.

2. Yunus Centre, Grameen Veolia Water Ltd. Retrieved from https://www.muhammadyunus.org /index.php/ socialbusiness/grameen-veolia-water-ltd.

3. The sustainable development goals and the role of business. Retrieved from https://sdghub.com/ceo-guide/

4. Energy for development and poverty reduction; Improved Biomass Stoves for Bangladesh: Practice and Promise; August 9, 2010. Retrieved from https://www.energyfordevelopment.com/2010/08/bangladeshimproved-stoves-report.html

5. G. Duncan Fullerton, Nigel Bruce and B. Gordon_Stephen, 'Indoor air pollution from biomass fuel smoke is a major health concern in the developing world', Trans R Soc Trop Med Hyg., Vol. 102, no. 9, September, 2008 pp. 843-851. Retrieved from https://www.ncbi.nlm.nih.gov/pmc/articles/PMC2568866/\#bib $\underline{7}$

6. K.R. Smith, 'Fuel combustion, air pollution exposure, and health: the situation in developing countries', Annual Review Energy Environment, Vol.18, 1993 pp.529-566.

7. Improved Cookstoves and Better Health in Bangladesh, Lessons from Household Energy and Sanitation Programs, Final Report, June 2010. Retrieved from: https://drive.google.com $\quad$ /file/d/0B7frijhUtgUMWNjODVhZTYtYjA4NC

00NGUwLThkZmItZjEyZmE2NGE1MThh/view?ddrp=1\&hl =en\#

8. WHO fact sheet, ambient (outdoor) air quality and health, 2 May 2018. Retrieved from: http://www.who.int/en/newsroom/fact-sheets/ detail/ambient-(outdoor)-air-quality-andhealth

9. K. P. Pant, S. K. Pattanayak, and M. B. M. Thakuri 'Climate change, cook stoves, and coughs and colds: Thinking global and acting local in rural Nepal', In S. Barrett, K. G. Maler, \& E. Maskin (Eds.), Environment and development economics: Essays in honour of Sir Partha Dasgupta, (pp.143-168). Oxford, England: Oxford University Press. 2014.

10. E. Boy, N. Bruce, and H. Delgado, 'Birth weight and exposure to kitchen wood smoke during pregnancy in rural Guatemala', Environ. Health Perspect, Vol.110, 2002 pp.109114.

11. The Partnership for Clean indoor air. Grameen Shakti. Retrieved from http://www.pciaonline.org/grameenshakti

12. P. Wilkinson, K. R. Smith, M. Davies, H. Adair, B.G. Armstrong, M. Barrett, N. Bruce, A. Haines, I. Hamilton, T. Oreszczyn, I. Ridley, C. Tonne and Z. Chalabi, 'Public health benefits of strategies to reduce greenhouse-gas emissions: household energy', The Lancet, Vol 374, December 5, 2009.

13. WHO, 2007

14. Central bureau of statistics 2004

15. National Institute of Population Research and Training; Bangladesh Maternal Mortality and Health Care Survey
(BMMS) 2016. Retrieved from: https://www.measureevaluation.org/resources/publications/tr$\underline{17-218}$

16. Digital health trackers making pregnancy and delivery safer for mother and her newborn, May 2017

17. Dhaka Tribune; COEL - The smart bangle for maternal wellness; Jul 24, 2018Retrieved from: https://www.dhakatribune.com/magazine/weekendtribune $/ 2017 / 05 / 03 /$ coel-smart-bangle-maternal-wellness 18. Social impact of COEL. Retrieved from: http://www.tsi.com.bd/products/coel/

19. O. Sangpetch and A. S. Faculty, 'Security Context Framework for Distributed Healthcare IoT Platform', Internet Things Big Data Technol. Next Gener. Healthc, 2016 pp. 7176

20. Global Continuous Glucose Monitoring Market to Reach $\$ 20.7 \mathrm{~B}$ by 2022 (December 13 2017). Retrieved from https://www.bccresearch.com/pressroom/hlc/globalcontinuous-glucose-monitoring-market-to-reach-\$207b-by2022. 